\title{
Commentary
}

\section{Naso-maxillary complex in size, position and orientation in surgically treated and untreated individuals with cleft lip and palate}

acial bone growth, intramembranous in origin, is governed by Functional Matrix Theory, which is related to mechanical forces, eruption of teeth, expansion of nasal and oral cavities and sinuses. ${ }^{[1,2]}$ Maxillary tuberosity, which is thought to be a growth centre, is predominantly responsible for the lengthening of maxillary arches. As proposed by Scott, ${ }^{3 \mid}$ the cartilage of nasal septum responds to pressure and expansion, leading to growth of maxilla anteriorly and inferiorly. The growth of face is also stimulated by functional

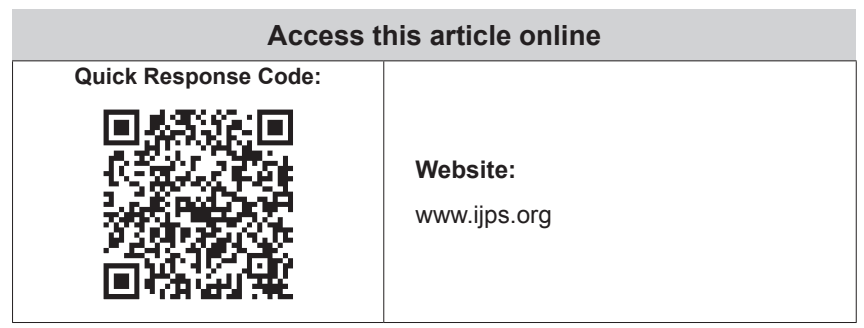

demands like expansion of respiratory volume, and therefore obstruction of nostrils may affect and deviate the facial growth. The mandibular growth is modified according to the growth of maxilla. Various dynamic orthopaedic and orthodontic treatments in young babies have not proved to be stimulating the growth, but some of them definitely have shown adverse effects on the maxillary growth. ${ }^{[4]}$

The management of cleft lip and palate is controversial because of unpredictability of the outcome following various surgical procedures. In addition, very little is known about embryological anatomy and aetiology of cleft lip and palate, associated hypoplasia and deficiency of tissue and factors governing the growth of facial skeleton.

The following factors affect the growth of cleft maxilla:

Indian Journal of Plastic Surgery January-April 2012 Vol 45 Issue 1 


\section{INTRINSIC FACTORS}

It is appropriate to assume that embryological variability according to aetiology of cleft lip and palate presents different growth potential with variable hypoplasia. Many studies have reported unoperated cleft lip and palate patients with protruded dentoalveolar segment and retruded skeletal base to have inhibited growth in antero-posterior direction..$^{[5-7]}$ The group with untreated cleft lip and palate without surgical trauma has been documented to be smaller than the control group in a Sri Lankan study, ${ }^{[8]}$ which suggested some degree of intrinsic hypoplasia. In addition to this, the familial facial patterns run in families, affecting this complex issue of growth of maxilla in cleft.

\section{FUNCTIONAL FACTORS}

In addition to embryology, the functional factors like abnormal position of tongue or nasal obstruction leading to oral breathing modify the growth potential and direction. ${ }^{[9]}$ Various functional manipulations in the form of orthodontic treatment of maxilla also modify the growth.

\section{SURGICAL TRAUMA}

Surgery definitely adversely affects the growth, and this depends on the extent of scar formation, which is related to different types of incisions on palate, raising of mucoperiosteal flap, raw areas on palate and tendencies of scar formation of different individuals. Surgery affects the growth in the following ways: 1. tight lip closure and 2. scarring of palate and post-tuberosity area. Both lip and palate repair have independently shown adverse effects on maxillary growth. ${ }^{[10]}$ The other important factors are experience of the surgeon and tissue handling rather than technique and procedure of the repair. There are no randomised controlled trials supporting any surgical technique or protocol to have a beneficial effect for maxillary growth. Though inter-centric studies provide us some insight into the outcome of different protocols, it is confounded by many factors like experience of the surgeon, associated manipulation and ethnicity of population. ${ }^{[11]}$

And therefore, for any realistic growth study in cleft lip and palate, it is critical to record every aspect of the cleft like embryological diagnosis, ${ }^{[12]}$ inherent hypoplasia, familial tendencies, surgical protocol, experience of surgeon and scarring tendencies of an individual.

This study in Indian population is one of the many similar studies showing adverse effect of surgical correction in cleft lip and palate individuals. ${ }^{[13]}$ The details of surgical procedure, exact age of surgeries and experience of surgeons would have added value to the article.

\section{Jyotsna Murthy}

Department of Plastic Surgery, Chief Coordinator, Cleft and Craniofacial Center, Sri Ramachandra University, Chennai, India. E-mail: murthyjyotsna@gmail.com

\section{REFERENCES}

1. Enlow DH. Introductory concepts of the growth process. Handbook of facial growth. Phildelphia: WB Saunders; 1975. p. 12.

2. Moss ML. The primary role fo functional matrices in facial growth. Am J Orthod 1969;55:566.

3. Scott JH. The cartilage of nasal septum. Br Dent J 1953;95:37-43.

4. Berkowitz S. A comparison of treatment results in complete bilateral cleft lip and palate using a conservative approach versus Millard-Latham PSOT procedure. Sadowsky PL(ed.), Seminar on orthodontics cleft lip and palate. Philadelphia: Saunders; 1996b. p. 169.

5. Iseikwe MC, Sowemimo GO. Cephalometric findings in a normal Nigerian population sample and adjust Nigerians with unrepaired cleft. Cleft Palate J 1984;21:323-8.

6. Bishara SE, Jakobsen JR, Krause JC, Sosa-Martinex R. Cephalometric comparisons of individuals from India and Mexico with unoperated cleft lip and palate. Cleft Palate $J$ 1986;23:116-25.

7. Shetye P. Facial Growth of adults with unoperated clefts. Clin Plast Surg 2004;31:361-71.

8. Mars M, James DR, Lamabadusuriya SP. The Sri Lankan Cleft Lip and Palate Project: The unoperated cleft lip and palate. Cleft Palate J 1990;27:3-6.

9. Smahel Z, Trefny P, Formanek P, Mullerova A, Peterka M. Three-dimentional morphology of the palate in subject with unilateral complete cleft lip and palate at the stage of permanent dentition. Cleft Palate Craniofac J 2004;41:416-23.

10. Kuijpers-Jagtman AM, Long Jr RE. State of art: The influence of surgery and orthopedic treatment on maxillofacial growth and maxillary arch dimensions in patients treated for orofacial clefts. Cleft Palate Craniofac J 2000;37:527.

11. Ross RB. Treatment variables affecting facial growth in cleft lip and palate. Part 6: Techniques of palate repair. Cleft Palate J 1987f;24:64-70.

12. Carstens $\mathrm{MH}$, Ewings E. Neuroembryology and functional anatomy of craniofacial clefts. Indian J Plast Surg 2009;42:19-34.

13. Ross RB. Treatment variables affecting facial growth in complete unilateral cleft lip and palate. Cleft Palate J 1987;24:54-63.

How to cite this article: Murthy J. Naso-maxillary complex in size, position and orientation in surgically treated and untreated individuals with cleft lip and palate. Indian J Plast Surg 2012;45:75-6. 